\title{
Polypeptide and antigen profiles of Cryptobia salmositica, C. bullocki and C. catostomi (Kinetoplastida: Sarcomastigophora) isolated from fishes
}

\author{
Patrick T. K. Woo, Philip T. Thomas \\ Department of Zoology, University of Guelph, Guelph, Ontario, Canada N1G 2W1
}

\begin{abstract}
Polypeptide and antigen profiles of Cryptobia salmositica (virulent and avirulent strains), C. bullocki and C. catostomi were compared using SDS-PAGE and Western immunoblot. The avirulent strain of C. salmositica had 5 fewer bands than the virulent strain (21 bands) which is, perhaps, related to loss of virulence. C. catostomi had the highest number of bands (23) and a different banding pattern than the other 2 species. Although the 3 species had several bands of similar molecular mass, they were antigenically distinct. The avirulent and virulent strains of $C$. salmositica had several cross-reacting bands when probed with antiserum against the virulent strain. There were, however, no cross-reactions between $C$. salmositica and the other 2 species except for a band of $66 \mathrm{kD}$. We tentatively suggest that pathogenic and non-pathogenic species of Cryptobia have different polypeptide profiles and are antigenically distinct. SDS-PAGE followed by Western immunoblot may be a useful procedure to distinguish species of Cryptobia from various hosts and also to determine their phylogenetic relationships.
\end{abstract}

\section{INTRODUCTION}

Cryptobia spp. (Kinetoplastida: Sarcomastigophora) have been described from gills, body surface, digestive system and/or blood of fresh water and marine fishes. Some are pathogenic while many have not been shown to cause disease (Woo 1987). Cryptobia salmositica, C. bullocki and C. catostomi are hemoflagellates of fishes in North America; the first two are pathogenic, the third is non-pathogenic.

Cryptobia salmositica is a pathogen of salmonids on the Pacific coast. It is normally transmitted by Piscicola salmositica (Hirudinea: Annelida) (Becker \& Katz 1965a,b); however, direct transmission between fish has also been demonstrated (Bower \& Margolis 1983, Woo \& Wehnert 1983). Trout infected with C. salmositica develop anorexia, exophthalmia, abdominal distension with ascites, general oedema, splenomegaly and a microcytic and hypochromic anaemia. High mortalities occur during the acute phase of the disease (Woo 1979, 1987). Continuous in vitro culture of the parasite resulted in an avirulent strain that not only did not cause disease, but also protected trout from the disease when they were challenged with the virulent strain (Woo \& Li 1990)

Cryptobia bullocki is pathogenic to flatfish along the Atlantic coast. Clinical signs include lethargy, anaemia, abdominal distension with ascites and splenomegaly. Leech Calliobdella vivida are the vector (Burreson $1982 \mathrm{a}, \mathrm{b})$.

Cryptobia catostomi is a non-pathogenic hemoflagellate in white suckers in Ontario, Canada. Its vector is unknown. Although high parasitaemias occurred in experimental infections, no clinical signs were evident (Bower \& Woo 1977a,b).

Nothing is known about polypeptides and their antigenicity in piscine hemoflagellates. The objectives of the present study were: (1) to compare the polypeptide and antigen profiles of Cryptobia salmositica (virulent and avirulent strains), C. bullocki and $C$. catostomi using sodium dodecyl sulfate-poly acrylamide gel electrophoresis (SDS-PAGE) and Western immunoblot; (2) to determine if there are specific patterns in the polypeptide and/or antigen profiles characteristic of pathogenic and non-pathogenic forms. 


\section{MATERIALS AND METHODS}

Maintenance of parasites and preparation of antigen. For studies on Cryptobia salmositica virulent strain, blood from a heavily infected rainbow trout Oncorhynchus mykiss was withdrawn asceptically by cardiac puncture and added to Minimum Essential Medium supplemented with $25 \%$ foetal bovine serum (Woo \& Li 1990). The culture bottles were kept upright overnight at $10^{\circ} \mathrm{C}$ to sediment fish blood cells. Parasites and some supernatant fluid were carefully removed (without blood cells) and inoculated into fresh culture medium and incubated at $10^{\circ} \mathrm{C}$. Parasites from these cultures were harvested $10 \mathrm{wk}$ after inoculation, washed 3 times in cold-blooded vertebrate Ringer's (CBVR) solution (centrifugation at $13000 \times g$ for 6 min each time at $4^{\circ} \mathrm{C}$ ) and resuspended in cold CBVR. The number of parasites was determined using a haemocytometer (Archer 1965) and the suspension was freeze-thawed to lyse the parasites. Total protein concentration of the lysed parasites was estimated according to Bradford (1976); the parasite suspension was stored at $-100^{\circ} \mathrm{C}$.

Regarding Cryptobia salmositica avirulent strain, the strain was the one used by Woo \& Li (1990). It was derived from the virulent strain and had been in continuous culture $\left(10^{\circ} \mathrm{C}\right)$ for more than 2 yr. Parasites were harvested and their number determined. After estimating the protein concentration of the suspension (see above), it was stored at $-100^{\circ} \mathrm{C}$.

Cryptobia bullocki was originally isolated from the blood of a southern flounder Paralichthys lethostigma. This strain was serially subcultured at $10^{\circ} \mathrm{C}$ in MEM supplemented with foetal bovine serum since 1985 and was shown to be still infective to fish (E. M. Burreson pers. comm.). Number of parasites and protein concentration of the suspension were determined (see above); the parasite suspension was stored at $-100^{\circ} \mathrm{C}$.

Cryptobia catostomi was originally isolated from blood of a white sucker Catostomus commersoni and cultured in MEM supplemented with foetal bovine serum at $10^{\circ} \mathrm{C}$. Parasites were subcultured $10 \mathrm{wk}$ postinoculation. Number of parasites and protein concentration of the suspension were determined (see above); the parasite suspension was stored at $-100^{\circ} \mathrm{C}$.

The suspensions of the 3 species of Cryptobia stored at $-100^{\circ} \mathrm{C}$ were analysed using SDS-PAGE and Western blot techniques

Dimensions of the parasites. Diameter and volume of the parasites were estimated using a Coulter Counter (Model ZM) connected to a Coulter Channelyzer 256 (Coulter Electronics of Canada Ltd., Burlington, Ontario, Canada).

Infectivity of the parasites. Cryptobia salmositica (virulent and avirulent strains) and $C$. catostomi were inoculated intraperitoneally into naive rainbow trout and white sucker respectively (ca 50000 parasites fish $^{-1}$ ) and blood of the fishes was examined for parasites at $4 \mathrm{wk}$ post-inoculation using the haematocrit centrifuge technique (Woo \& Wehnert 1983).

SDS-PAGE. Proteins were separated, according to the discontinuous gel system of Laemmli (1970), using a Mini-Protean II dual slab cell (Bio-Rad Laboratories (Canada) Ltd., Mississauga, Ontario, Canada). Appropriate dilutions of parasite suspensions were made with CBVR to obtain same number of parasites or same amount of total protein. Parasite suspensions were mixed with an equal volume of reducing buffer and heated at $95^{\circ} \mathrm{C}$ for $8 \mathrm{~min}$ to denature the proteins. Samples were loaded into the stacking gel and electrophoresed into a $13 \%$ running gel at $150 \mathrm{~V}$ for $40 \mathrm{~min}$. Two gels were run simultaneously, one to be stained with Coomassie Brilliant Blue, the other for Western immunoblot. The gel stained using Coomassie Brilliant Blue was destained and the location and molecular mass of the bands were determined using a densitometer (Fisher Scientific, Toronto, Ontario, Canada) with reference to protein standards of known molecular weights on the same gel.

Antiserum against Cryptobia salmositica. A sample of blood was collected from each of 2 adult female rabbits. Serum was separated from the blood (preimmune serum), heat-inactivated $\left(56^{\circ} \mathrm{C}, 30 \mathrm{~min}\right)$ and stored at $-100^{\circ} \mathrm{C}$. The rabbits were immunized with $3 \times$ washed virulent strain of $C$. salmositica (suspended in Freund's incomplete adjuvant) by subcutaneous inoculation $\left(5 \times 10^{6}\right.$ parasites rabbit $\left.{ }^{-1}\right)$. At $5 \mathrm{wk}$ postimmunization, each rabbit received a booster of $2 \times 10^{6}$ parasites in incomplete adjuvant. A second booster of $2 \times 10^{6}$ parasites without adjuvant was given to each rabbit 1 wk later. The rabbits were sacrificed $9 \mathrm{~d}$ later and their blood collected. The antiserum was separated, heat-inactivated and stored at $-100^{\circ} \mathrm{C}$.

Western immunoblot was done on nitrocellulose membrane using a Mini-Trans-blot Electrophoretic Transfer Cell (Bio-Rad Laboratories, Canada Ltd.). Electrophoretic transfer of polypeptide bands from the gel to the nitrocellulose membrane was for $1 \mathrm{~h}$ at $100 \mathrm{~V}$. After transfer, the surface of the membrane was blocked using a 3\% solution of Gelatin. The membrane was incubated overnight with a 1:6000 dilution of rabbit-anti virulent Cryptobia salmositica antibody (first antibody) and for $2 \mathrm{~h}$ with a 13300 dilution of goat-anti-rabbit antibody (second antibody) conjugated to alkaline phosphatase. Colour development was for $20 \mathrm{~min}$, after which the membrane was washed in distilled water for 20 min ( 5 changes) to stop the reaction. The membrane was dried between filter papers and stored away from light.

Statistics. Diameter and volume of parasites were compared pairwise using Student's t-test (Sokal \& Rohlf 1981). 


\section{RESULTS}

\section{Dimensions of the parasites}

Cryptobia catostomi was the largest, C. bullocki the smallest (by diameter and volume) among the 3 species. The avirulent strain of $C$. salmositica was smaller than the virulent strain. The size differences between the parasites were statistically significant (Table 1 ).

\section{Infectivity of the parasites}

The 3 species of Cryptobia (4 strains) used in the present study were infective to their respective fish hosts.

When SDS-PAGE was done using various numbers of parasites of the virulent strain of Cryptobia salmositica (ca $25 \times 10^{6}, 50 \times 10^{6}$ and $100 \times 10^{6} \mathrm{ml}^{-1}$ ), the maximum numbers of polypeptide bands were obtained with $50 \times 10^{6}$ and $100 \times 10^{6}$ parasites $\mathrm{ml}^{-1}$. The avirulent strain at the above concentrations gave fewer and fainter bands. Since the avirulent strain was smaller than the virulent strain (Table 1), parasite suspensions with the same amount of total protein (ca $1.1 \mu \mathrm{g} \mathrm{ll}^{-1}$; equivalent to $\mathrm{ca} 100 \times 10^{6}$ virulent $C$. salmositica and $400 \times 10^{6}$ avirulent $C$. salmositica) were used in subsequent SDS-PAGE.

The number of polypeptide bands from the 3 species of Cryptobia (same amount of total protein) according to densitometer tracings were: 21 and 16 (C. salmositica virulent and avirulent strains respectively), 19 (C. bullocki) and 23 (C. catostomi). These bands were arbitrarily divided into 3 groups: Group I comprising polypeptides with molecular mass between 20 and $35 \mathrm{kD}$; Group II, between 36 and $105 \mathrm{kD}$; Group III, between 106 and $1800 \mathrm{kD}$ (Table 2). The virulent strain of C. salmositica had more polypeptide bands than the avirulent strain. C. catostomi had the highest number
Table 1. Cryptobia spp. Diameter and volume

\begin{tabular}{|c|c|c|}
\hline Parasite & Diameter $(\mu \mathrm{m})$ & Volume (fL) \\
\hline $\begin{array}{l}\text { C. salmositica } \\
\text { (virulent strain) }\end{array}$ & $5.36 \pm 0.05^{\circ+}$ & $80.64 \pm 2.36^{\circ+}$ \\
\hline $\begin{array}{l}\text { C. salmositica } \\
\text { (avirulent strain) }\end{array}$ & $4.84 \pm 0.08^{\circ}$ & $59.40 \pm 2.95^{\circ}$ \\
\hline C. bullocki & $4.39 \pm 0.03^{\circ}$ & $44.27 \pm 0.90^{\circ}$ \\
\hline C. catostomi & $5.72 \pm 0.17^{\cdot+}$ & $98.33 \pm 8.14^{\bullet+}$ \\
\hline \multicolumn{3}{|c|}{$\begin{array}{l}\text { Significantly different, } \mathrm{p}<0.001 \\
+ \text { Significantly different, } p<0.05 \\
\text { Dimensions for each species represent mean and standard } \\
\text { deviation of } 3 \text { cultures }\end{array}$} \\
\hline
\end{tabular}

of bands among the 3 species of Cryptobia. All 3 species had several bands of similar molecular mass (Table 2).

Both virulent and avirulent strains of Cryptobia salmositica had similar banding patterns in the range of 40 to $100 \mathrm{kD}$. However, the virulent strain had an extra band of ca $57 \mathrm{kD}$. C. bullocki had a pattern similar to the avirulent strain of $C$. salmositica, but lacked 2 bands ( 40 to $42 \mathrm{kD}$ ). These bands were also present in the virulent strain of C. salmositica. C. catostomi had a different pattern of bands from the other 2 species (Figs. 1 \& 2). The study was repeated twice and similar results were obtained.

\section{Western immunoblot}

Polypeptide bands of the virulent strain of Cryptobia salmositica showed the strongest immunological reaction when compared to those of the avirulent strain and of the other 2 species of Cryptobia. No reactions were evident with the polypeptide bands of $C$. bullocki and C. catostomi except for a band of ca $66 \mathrm{kD}$.

Table 2. Cryptobia spp. Molecular masses of polypeptides derived from SDS-PAGE

\begin{tabular}{|c|c|c|c|c|}
\hline $\begin{array}{l}\text { Mol. mass } \\
\text { grouping }\end{array}$ & $\begin{array}{c}\text { Cryptobia salmositica } \\
\text { virulent }\end{array}$ & $\begin{array}{l}\text { C. salmositica } \\
\text { avirulent }\end{array}$ & C. bullocki & C. catostomi \\
\hline $\begin{array}{l}\text { Group I } \\
(20-35 \mathrm{kD})\end{array}$ & $\begin{array}{l}22,23,24 \\
26,29,32 \\
35\end{array}$ & $\begin{array}{l}22,24,26 \\
30,33\end{array}$ & $\begin{array}{l}24,25,27 \\
28,30,31 \\
33\end{array}$ & $\begin{array}{l}22,23,24 \\
26,28,29 \\
33,35\end{array}$ \\
\hline $\begin{array}{l}\text { Group II } \\
(36-105 \mathrm{kD})\end{array}$ & $\begin{array}{l}40,41,47 \\
57,59,66 \\
78,88,105\end{array}$ & $\begin{array}{l}36,40,42 \\
49,60,70 \\
84,96\end{array}$ & $\begin{array}{l}36,39,47 \\
62,68,84 \\
96,105\end{array}$ & $\begin{array}{l}37,39,43 \\
53,64,75 \\
78,88,91 \\
105\end{array}$ \\
\hline $\begin{array}{l}\text { Group III } \\
(106-1800 \mathrm{kD})\end{array}$ & $\begin{array}{l}151,178 \\
274,617 \\
909\end{array}$ & $\begin{array}{l}124,468 \\
909\end{array}$ & $\begin{array}{l}117,195 \\
617,909\end{array}$ & $\begin{array}{l}132,241 \\
378,468 \\
1766\end{array}$ \\
\hline
\end{tabular}




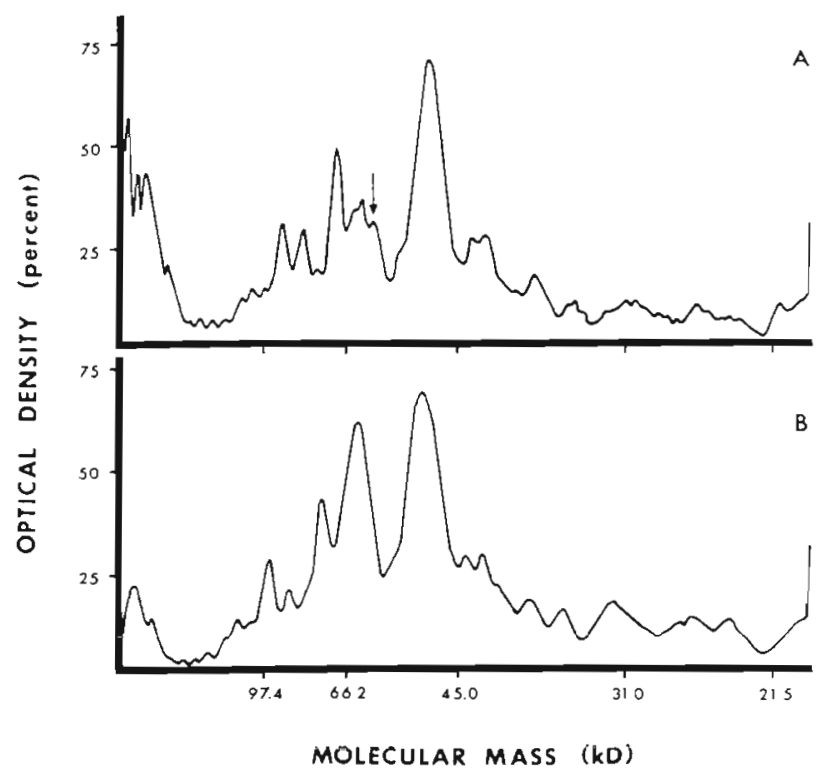

Fig. 1. Cryptobia salmositica. Densitometer tracings of polypeptide profiles of virulent (A) and avirulent (B) strains. Arrow: extra polypeptide band of ca $57 \mathrm{kD}$ in virulent strain

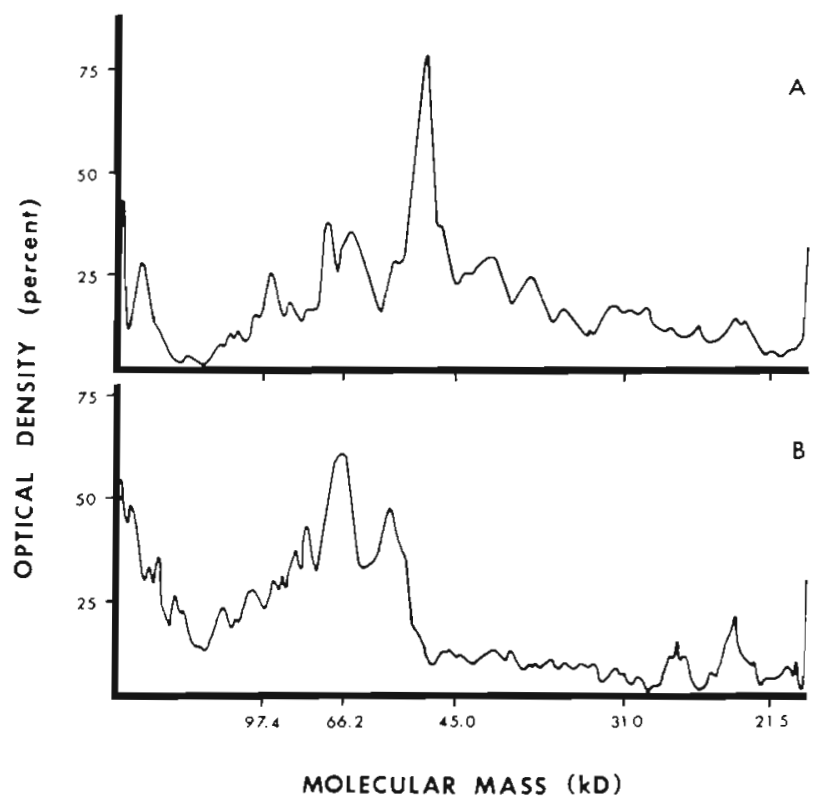

Fig. 2. Cryptobia bullocki (A) and C. catostomi (B). Densitometer tracings of polypeptide profiles

The polypeptide bands of the avirulent strain of $C$. salmositica gave a less intense reaction than those of the virulent strain. Also at least 5 bands in the molecular mass range 20 to $200 \mathrm{kD}$ that gave an immunological reaction in the virulent strain did not react in the avirulent strain (Fig. 3). None of the 3 species of Cryptobia reacted with the pre-immune serum. Similar results were obtained when the experiment was repeated.

\section{$1 \quad 2 \quad 3 \quad 4$}

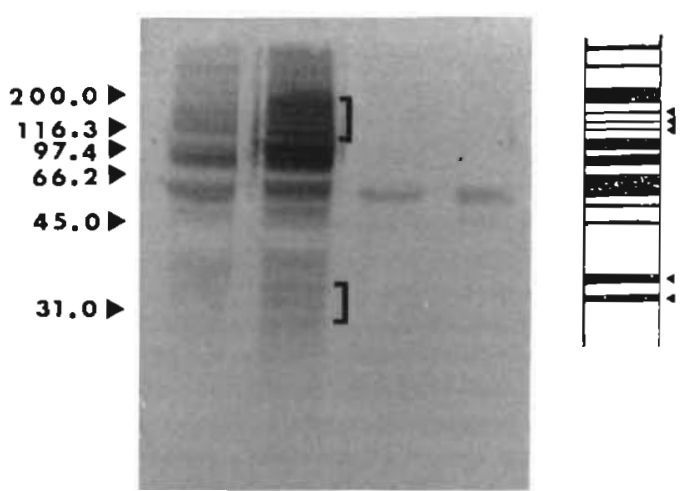

Fig. 3. Cryptobia spp. Antigens detected using Western immunoblot. The antiserum was against virulent $C$. salmositica. (1) avirulent C. salmositica; (2) virulent C. salmositica; (3) C. bullocki; (4) C. catostomi. Brackets: regions where there are differences in number of bands between virulent and avirulent $C$. salmositica. Right: Drawing of Western blot of virulent strain of C. salmositica; arrowheads: polypeptide bands not found in avirulent strain

\section{DISCUSSION}

Size difference between virulent and avirulent strains of Cryptobia salmositica is a contributing factor to the difference in the number of bands when same number of organisms was used. The smaller organism (avirulent strain) has less of certain polypeptides and these are not detected as distinct bands. However, the polypeptide profiles (SDS-PAGE) of the virulent and avirulent strains of $C$. salmositica were generally similar although the avirulent strain had fewer bands even when same amount of total protein was used (Fig. 1). Perhaps the loss of bands in the avirulent strain is related to the loss of virulence. Further studies are needed to confirm this suggestion.

In the Western immunoblot, certain bands of the avirulent strain did not react when probed with antiserum raised against the virulent strain (Fig. 3). This indicated that the bands were antigenically distinct. Nevertheless, the overall cross-reaction of the polypeptide bands of the avirulent strain points out that the basic antigenic nature of the parasite had not changed significantly as a result of attenuation. Woo \& Li (1990) showed that trout infected with the avirulent strain were protected from the disease when challenged with the virulent strain

The difference in number of polypeptide bands between the 3 species may largely be due to inherent biochemical differences between the species and hence, different types of proteins. This is supported by the fact that virtually no cross-reactions were found between Cryptobia salmositica and the other 2 species 
of Cryptobia although they had several polypeptides of similar molecular weights (Table 2).

The use of SDS-PAGE followed by western immunoblotting seems to be a good procedure to distinguish species because the blood forms of many species are morphologically indistinguishable (Woo 1987). This procedure may also be useful in determining the phylogenetic relationships between species isolated from different fishes.

The present study points to the antigenic distinctiveness of the 3 species of Cryptobia. There were no cross reactions between the polypeptide bands of the 3 species except for one band (ca $66 \mathrm{kD}$ ). The localization of this polypeptide in the organisms is not known; it may be a component of the flagella or cytoskeleton.

Cryptobia catostomi, a non-pathogenic parasite, had a different pattern of polypeptide bands from the other 2 species of Cryptobia. Although the avirulent strain of C. salmositica also did not cause a disease in fish, its polypeptide profile was generally similar to that of the virulent strain. This is not surprising because the avirulent strain was derived from the virulent strain. Also common antigenicity between the 2 strains is revealed by the cross reaction of the polypeptides of the avirulent strain with antiserum raised against the virulent strain (present study) and also by the protection against the disease in fish infected with the avirulent strain and challenged with the virulent strain (Woo \& Li 1990).

Our study tentatively suggests that pathogenic and non-pathogenic species of Cryptobia have different polypeptide profiles and this may be a useful distinguishing character. This will have to be confirmed with a more extensive study of more species of pathogenic and non-pathogenic Cryptobia isolated from different hosts and from different geographical locations.

Acknowledgements. We are very grateful to Dr E. M. Burreson, Virginia Institute of Marine Science, College of William and Mary, Gloucester Point, Virginia, USA for providing the culture of Cryptobia bullocki and for testing the infectivity of the parasite. This study was supported by grants from the Natural Sciences and Engineering Research Council, Canada, and the Department of Fisheries and Oceans, Canada, to P.T.K.W

Responsible Subject Editor: W. Körting, Hannover, Germany

\section{LITERATURE CITED}

Archer, R. K. (1965). Haematological techniques for use on animals. Blackwell Scientific Publications, Oxford

Becker, C. D., Katz, M. (1965a). Infections the hemoflagellate, Cryptobia salmositica Katz, 1951, in freshwater teleosts of the Pacific coast. Trans. Am. Fish. Soc. 94: 327-333

Becker, C. D., Katz, M. (1965b). Transmission of the hemoflagellate, Cryptobia salmositica Katz, 1951, by a rhynchobdellid vector. J. Parasit. 51: 95-99

Bower, S. M. Margolis, L. (1983). Direct transmission of the haemoflagellate Cryptobia salmositica among Pacific salmon (Oncorhynchus spp.). Can. J. Zool. 61. 1242-1250

Bower, S. M., Woo, P. T K. (1977a). Morphology and host specificity of Cryptobia catostomi n. sp. (Protozoa: Kinetoplastida) from white sucker (Catostomus commersoni) in southern Ontario. Can. J. Zool. 55: 1082-1092

Bower, S. M., Woo, P. T. K. (1977b). Division and morphogenesis of Cryptobia catostomi (Protozoa: Kinetoplastida) in the blood of white sucker (Catostomus commersoni). Can. J. Zool. 55: 1093-1099

Bradford, M. M. (1976). A rapid and sensitive method for the quantitation of microgram quantities of protein utilizing the principle of protein-dye binding. Analyt. Biochem. 72: 248-254

Burreson, E. M. (1982a). Trypanoplasmiasis in flounder along the Atlantic coast of the United States. In: Anderson, D. P., Dorson, M., Dubourget, Ph. (eds.) Antigens of fish pathogens. Collection Fondation Marcel Merieux, France, p. 251-260

Burreson, E. M. (1982b). The life cycle of Trypanoplasma bullocki (Zoomastigophorea: Kinetoplastida). J. Protozool. 29: $72-77$

Laemmli, U. K. (1970). Cleavage of structural proteins during the assembly of the head of bacteriophage T4. Nature, Lond 227: 680-685

Sokal, R. R., Rohlf, F. J. (1981). Biometry, 2nd edn. W. H Freeman and Company, New York

Woo, P. T K. (1979). Trypanoplasma salmositica: experimental infections in rainbow trout Salmo gairdneri. Expl. Parasit. $47: 36-48$

Woo, P. T K. (1987). Cryptobia and cryptobiosis in fishes. In: Baker, J. R., Müller, R. (eds.) Advances in parasitology Vol. 26. Academic Press, London, New York. p. 199-237

Woo, P. T. K. Wehnert, S. D. (1983). Direct transmission of a hemoflagellate, Cryptobia salmositica (Kinetoplastida Bodonina) between rainbow trout under laboratory conditions. J. Protozool. 30: 334-337

Woo, P. T K. Li, S. (1990). In vitro attenuation of Cryptobia salmositica and its use as a live vaccine against cryptobiosis in Oncorhynchus mykiss. J. Parasit. 76: 752-755

Manuscript first received: March 3, 1991

Revised version accepted: June 6, 1991 